\title{
Time perception, vigilance and decision theory ${ }^{\prime}$
}

G. VON STURMER

MONASH UNIVERSITY

A statistical decision hypothes is is outlined to account for a progressive lengthening of judgments which occurs when a series of reproductions of a time interval is made without interpolation of a standard. Three experiments are reported in which it is found that this serial effect can be manipulated by hypothetical payoff conditions, that the effect still occurs when subjects are told to count while making their judgments, and that two successive judgments are sufficient to demonstrate the effect if enough subjects are used. The phenomenon is related to recent studies of vigilance in which statistical decision theory has been applied. It is suggested that serial reproductions of time intervals may perhaps be a more sensitive index of the factors underlying vigilance than the traditional measures involving long sessions with weak, sporadic signals.

When a series of reproductions of an interval of time is made without interpolation of a standard, the judgments progressively lengthen (Falk \& Bindra, 1954). In an experiment by von Sturmer (1966) Ss made 20 successive reproductions of a 5 sec interval, and background stimulation was varied on selected trials. On trials with constant background reproductions got longer and longer, but when the monotonous situation was interrupted by a flashing light, or a bell, reproductions which were shorter than those on preceding trials were observed. It was argued that under monotonous conditions a decrement in vigilance for time-relevant cues occurred, and failure to detect these cues reduced the amount of time perceived to elapse during a given period. Reproduced intervals therefore had to progressively lengthen to match the remembered standard. Variation in background conditions restored the S's level of alertness and resulted in shorter reproductions.

Broadbent and Gregory (1963) have demonstrated the usefulness of a statistical decision theory approach to vigilance. A similar approach, appropriate to the serial time estimation task, has been devised as an alternative to von Sturmer's (1966) vigilance and arousal hypothesis.

When a $\mathrm{S}$ makes a reproduction of a time interval he cannot be absolutely certain when to end his judgment. Any decision he does make must involve some degree of risk that the interval is too short or too long. At the moment of the beginning of the reproduction the probability that the judgment will be too short if ended immediately will be 1.0. As time elapses the probability that too little time has passed must decline, while the probability that the interval is too long is rising. Ideally the $\mathrm{S}$ should make his decision to end the judgment when the probability of the interval being too short is 0.5 . However, he will seldom, if ever, make identical judgments from trial to trial. That is, the moment in objective time when the subjective probability is 0.5 that the judgment is too short will vary from trial to trial. With short standard intervals $(5-10 \mathrm{sec})$, the range over which any variation can occur, however, is restricted at the lower end. It is not restricted, within practical limits, at the upper end. Because the boundaries within which the $S$ makes a probabilistic decision to terminate his judgment of a short interval are thus unequally restricted, it follows that variations above an earlier obtained value are more likely than variations below it. A serial effect must occur. Judgments will progressively increase in duration.

The above view suggested three experiments. Each of these will be described and discussed in the order in which they were performed.

\section{EXPERIMENT 1}

This was an exploratory experiment which set out to examine the serial effect in time estimation when Ss were instructed to end each judgment when the probability was either greater or less than 0.5 that the judgment would be too short.

\section{Procedure}

Blindfolded Ss were asked to tap a Morse key at $8 \mathrm{sec}$ intervals, without counting. The key was linked with a pen recorder which was run at $5 \mathrm{~mm} / \mathrm{sec}$ when judgments were being recorded. Two sets of instructions were used. Under Set $S$ (favoring shorter judgments), Ss were told always to press the key the moment there was the slightest possibility that enough time had elapsed since the last tap. They were never to risk their judgments being too long. Under the second set of instructions, Set L (favoring longer estimates), Ss were asked to press the key only when they were absolutely certain that enough time had elapsed since the last tap. They were never to run the risk that their judgments would be too short. The standard interval was presented, as the time between two clicks made by an electronic timer, once before each set of judgments under each experimental condition.

Fourteen Ss, seven men and seven women, were used. Each made 50 judgments under each instruc- 
Table 1. Mean judged intervals (in sec.) for two instruction conditions and results of Friedman's tests.

\begin{tabular}{lrrrrr} 
Instructions/trials & 1 & 20 & 50 & $X_{r}^{2}$ & $p$ \\
\hline L first & 12 & 16 & 22 & 9.50 & $<.01$ \\
L second & 14 & 22 & 27 & 6.33 & $=.052$ \\
S first & 8 & 11 & 17 & 1.75 & $>.43$ \\
S second & 11 & 12 & 11 & 0.64 & $>.77$ \\
\hline
\end{tabular}

tion condition, half in the order SL and half in the order LS. Assignment to orders was random. One $S$ was omitted because she could not complete the experiment before an appointment. Judgments were measured on on Trials 1, 20, and 50 under each condition.

\section{Results}

Mean estimates in seconds obtained under each instruction condition on each of the recorded trials are presented in Table 1.

A Friedman's test was applied to the ordered raw data in each instruction category. The obtained values of $\chi_{r}^{2}$ and $p$ are shown in Table 1 also.

\section{Discussion}

This experiment showed that steeper serial gains are obtained when Ss are instructed to avoid the risk of short judgments than when they are told to avoid the risk of long judgments. However, although these data are fairly clear, a second experiment was designed with different instructions, as some Ss had remarked that they were not sure what was required of them.

\section{EXPERIMENT 2}

\section{Procedure}

The $S$ was given a pencil and paper and told to draw the shortest line which could possibly be $7 \mathrm{~cm}$. Under this he was told to draw the longest line which could possibly be $7 \mathrm{~cm}$. The second line was usually longer than the first. The $S$ was then told to draw the line he would draw if he were given 100 dollars for absolute accuracy, but would lose 50 dollars for every centimeter it was too short and 1 cent for every centimeter it was too long. These rules were then reversed, and in all cases the first line was longer than the second. It was explained to the $S$ that the line drawing exercise was simply to familiarize him with optimal responses to differing hypothetical payoff conditions and that these rules would now be applied to a time estimation task.

In the time estimation task the $S$ was required to tap a Morse key at 10 seci intervals without counting. Under the $L$ condition (favoring longer judgments), the $S$ was told to imagine he had been given 100 dollars. If he was completely accurate he could keep the money. But for every second by which each judgment was too short he would lose 50 dollars, and for every second by which each judgment was too long he would lose 1 cent. Under the S condition (favoring shorter judgments) the payoff instructions were reversed. The method of production was used and blindfolds were worn. Twenty judgments were recorded.

Twenty Ss, 10 men and 10 women, were assigned randomly but with equal sex distribution to the $S$ or $\mathrm{L}$ instruction conditions.

\section{Results}

The mean of the first 10 trials was compared with the mean of the last 10 trials for each S. Instruction group means are recorded in Table 2.

To test the difference between serial effects under the two conditions a gain score (sum of Trials 11-20 minus sum of trials 1-10) was calculated for each S. A $t$ test for unrelated samples was applied to these scores in the two instruction groups $(t=2.07$, $d f=18, p<.05$ ). A one-tailed test was used as it was, in fact, expected that the $L$ group would show the largest gain. Sign tests, also one-tailed, on the direction of change from the first 10 trials to the last 10 trials showed a significant number of L Ss gave a serial effect $(p=.011)$, but this was not so for $S s$ in the $S$ condition $(p=.377)$.

\section{Discussion}

This study confirmed the finding of the first experiment that the serial effect can be manipulated by a hypothetical payoff-as would be expected in statistical decision theory.

\section{EXPERIMEN T 3}

This experiment was concerned with changes in the serial effect when a $\mathrm{S}$ was asked directly to make his judgments in relation to a particular level of confidence about their lengths. In addition, Ss were also told to count silently at the rate of one per sec (since the effect of counting was not known), and an attempt was made in the analysis to see how early in a series of such judgments the effect would become reliably measurable.

\section{Procedure}

Each $S$ was shown a vertical lime marked off in units which did not divide evenly into an inch. The $E$ named each unit in turn and asked whether the line to that point was longer or shorter than three

Table 2. Mean judgements (in sec) on first 10 and second 10 trials in Experiment 2 under differing hypothetical payoff conditions.

\begin{tabular}{cccc} 
Instructions/trials & $1-10$ & $11-20$ & gain \\
\hline L & 7.3 & 8.7 & 1.4 \\
S & 5.6 & 6.2 & 0.6 \\
\hline
\end{tabular}


inches. The $\mathrm{S}$ was permitted to answer "certainly shorter," "probably shorter," "probably longer," or "certainly longer." He was then shown where he changed his judgments. The points which were all judged shorter were bracketed. Then the probably shorter and probably longer regions were bracketed and finally, the region with no upper limit, which was judged certainly longer, was also indicated.

Subjects in the $S$ group were told that the experiment was concerned with the point marking the end of the certainly shorter region. Subjects in the $L$ group were told that the experiment was concerned with the point marking the beginning of the certainly longer region. A third group of $\mathrm{Ss}$, who were required simply to make best estimates, were told that the point with which the $\mathrm{E}$ was concerned was the one in the middle of the uncertainty region at the changeover from probably shorter to probably longer, i.e., the point where the probability that the line was shorter than three inches was equal to the probability that it was longer than three inches. These Ss were members of the 50/50 group.

Subjects were then told that they were to apply these principles to judgments of time in relation to a standard interval of $10 \mathrm{sec}$. Judgments were made by tapping a Morse key linked to a pen recorder as in earlier experiments. Subjects in the L group tapped the key each time at the first moment that was certainly longer than $10 \mathrm{sec}$; the Ss in the $S$ group tapped it at the last moment that was certainly shorter than $10 \mathrm{sec}$; and 50/50 Ss tapped the key at the moment of change from probably shorter to probably longer. Subjects were asked to count silently at the rate of $1 / \mathrm{sec}$, and wore blindfolds. No standard was presented. Six Ss, three men and three women, were assigned randomly to each group. Ten judgments were recorded.

\section{Resulis}

In Table 3 are the means in seconds of the first two judgments and of the first five and the last five judgments in each group.

Scores from the three groups were pooled, and judgments on Trials 1-5 were compared with those on Trials 6-10 using a $t$ test for related samples. The tendency for later judgments to be longer than earlier ones was significant with a two-talled test

Table 3.

Means (in sec) of judgements obtained on Trials 1 and 2 and Trials 1-5 and 6-10 obtained under differing instructions in Experiment 3.

\begin{tabular}{|c|c|c|c|c|}
\hline & $\begin{array}{c}\text { Trial } \\
1\end{array}$ & $\begin{array}{c}\text { Trial } \\
2\end{array}$ & $\begin{array}{c}\text { Trials } \\
1-5\end{array}$ & $\begin{array}{c}\text { Trials } \\
6-10\end{array}$ \\
\hline Group L & 9.8 & 11.5 & 11.3 & 12.6 \\
\hline Group $50 / 50$ & 8.5 & 9.8 & 10.1 & 10.7 \\
\hline Group S & 6.0 & 6.8 & 6.4 & 6.7 \\
\hline
\end{tabular}

$(p<.05)$. Trials 1 and 2 were then compared in the same way to see if the effect would be detectable this early in the process. It was, at the $p<.01$ significance level. Serial gain scores were calculated in each group as in the previous experiment, and these were examined for evidence of differences in magnitude of the serial effect between different instruction conditions. In the cases of both first vs second judgments and first five vs second five judgments, $F$ tests failed to reach the .05 level of significance.

\section{Discussion}

The third study demonstrated that the effect was reliably detectable when Ss were instructed to count and when only the first two judgments in the series were compared. Significantly different amounts of gain were not obtained in the different treatment groups although the data, with fewer Ss and fewer trials, did show the same trends as were observed in the first two studies.

\section{GENERAL DISCUSSION}

Together these three studies support the feasibility of a statistical decision model for serial time estimation, although the particular hypothesis outlined in the introduction may not be the most suitable. It is certainly imprecise. The data do not conflict with vigilance data except that the effect is measurable so early in the process. However, Mackworth (1963) obtained a decrement in the proportion of signals detected in a $6 \mathrm{~min}$ training period during which 40 signals were presented visually; thus, it may be that vigilance decrement usually has been regarded as a long-term process simply because the methods used in its investigation have presupposed this.

McGrath and O'Hanlon (1967) have related subjective rates of time to concurrent performance on a visual vigilance task. However, if time estimation and visual signal detection are both regarded as vigilance tasks, interpretation of the data they report is complicated by the possibility that the two tasks were concurrently in competition for basically the same class of responses. If implicit payoff conditions led to the favoring of one task over the other, and/or if some Ss were equally poor at both tasks, the situation would be even more cryptic. However, it is clear from their work that there is a relationship, if perhaps a complex one, between traditional measures of vigilance and the perception of duration.

The general view, therefore, that identical processes may underlie vigilance decrement and the serial effect in time estimation still seems tenable and appropriate for further exploration.

Streicher and Brantley (1967) demonstrated a serial effect with repeated drawing of lines from memory, which is similar to the effect obtained 
when judgments of duration are serially reproduced. The statistical decision hypothesis which is proposed here can be further tested in this type of situation if the range over which drawn lines may extend is physically limited by experimentally nominated starting points and varied positioning of right-hand margins. If the serial effect in line drawing were then found to vary with payoff conditions and changes in background alerting conditions, the notion of a single underlying process would be further strengthened.

The statistical decision approach described in the introduction does not account for the alerting effect obtained when background stimulation is varied on selected trials in a serial time estimation task. Neither, however, does this approach account for the effects of varied background obtained in traditional studies of vigilance (McGrath, 1963). Both arousal and decision theory approaches may have to be retained for a complete account of these phenomena.

\section{References}

Broadbent, D. E,, \& Gregory, $M$. Vigilance considered as a statistical decision. Brit. J. Psychol,, 1963, 54, 309-329.

Falk, J. L., \& Bindra, D. Judgement of time as a function of serial position and stress. J. exp. Psychol., 1954, 47, 279-282.

McGrath, J. J. Irrelevant stimulation and vigilance performance. In D. N. Buckner \& J. J. McGrath (Eds.), Vigilance: a symposium. New York: McGraw-Hill, 1963. Pp. 3-21.

McGrath, J. J., \& O'Hanlon, J. F. Temporal orientation and vigilance performance. Acta Psychol., 1967, 27, 410-419.

Streicher, H. W., \& Brantley, J. C. A repeated estimate effect in line drawing. Percept. mot. Skills, 1967, 24, 1054.

von Stumer, G. Stimulus variation and sequential judgements of duration. Quart. J. exp. Psychol., 1966, 18, 354-357.

(Accepted for publication November 4, 1967.) 